\title{
Social Media Usage in Health Communication and Its Implications on Public Health Security: A Case Study of COVID-19 in Zanzibar
}

\author{
Rashid Maalim Khamis ${ }^{1}$ \\ (iD) 0000-0002-8339-7415 \\ Yiqun Geng ${ }^{1 *}$ \\ (i) 0000-0002-0891-3563 \\ ${ }^{1}$ Communication University of China, Beijing, CHINA \\ *Corresponding author: gengyiqun@126.com
}

Citation: Khamis, R. M., \& Geng, Y. (2021). Social Media Usage in Health Communication and Its Implications on Public Health Security: A Case Study of COVID-19 in Zanzibar. Online Journal of Communication and Media Technologies, 11(1), e202101. https://doi.org/10.30935/ojcmt/9575

ARTICLE INFO

Received: 1 Sep 2020

Accepted: 27 Nov 2020

\begin{abstract}
Although social media are extensively employed in health communication promotion, their online and offline connection has rarely tested. This qualitatively study used a sample of 30 communication experts and health professionals to explore the role of social media in mitigating COVID-19 infections and its implications to people's health in Zanzibar. The findings revealed that social media are powerful platforms in providing health awareness information for mitigating COVID-19 and these platforms have enabled people to understand local medicines used to reduce the COVID-19 infections. In addition, there is high connection between online health information and offline people's health actions. Furthermore, Social media usage poses no threat to peoples' health during pandemic, however, there is high risk to affect those who lack Internet media literacy. Although social media poses no threat to some Internet media literate users, digital media literacy should be provided to all people in order to use these platforms more useful in mitigating infected diseases without compromising public health in Zanzibar and Africa at large.
\end{abstract}

Keywords: social media, health communication, public health security

\section{INTRODUCTION}

In the recent years, social media have emerged as indispensable tools in accelerating the fight against the pandemic worldwide (Chan et al., 2020; George et al., 2017; Honigsbaum, 2012; Merchant \& Lurie, 2020). As the number of social media users grow globally, the need for applying these new technologies for public health awareness including preventing and controlling strategy increased. According to Global Digital Review Report (2020), social media and other new technologies such as digital and mobile phones have become integral part for people's life worldwide. The report indicates that social media users have reached more than 3.8 billion whereas Internet users have passed 4.5 billion mark globally. Data also reveals that almost 60 per cent of the population over the world operate online, as the current trends propose that nearly half of the world population will be social media users before the end of 2020 year (Global Digital Review Report, 2020).

In Tanzania, according to Digital 2020 Report, the number of internet users have reached 14.72 million, whereas social media users surpassed 4.50 million in January, 2020. The data also indicates that the Internet penetration reached 25 percent in January, 2020 (Digital 2020 Report, 2020). This is a considerable increase of online users in the country, and this will have many implications to individual and community lives at large.

However, the robust discussion is how can social media be effectively used for health related communication in order to achieve favourable public health outcomes, at the same time what implications

Copyright ( 2021 by authors; licensee OJCMT. This article is an open access article distributed under the terms and conditions of the Creative Commons Attribution License (http://creativecommons.org/licenses/by/4.0/). 
will exert on health security. In the past few years, many scholars have focused on the usefulness and efficiency of social media in health promotion, revealing varied, and sometimes lack of convincing proof of usefulness in influencing public related health (Chou et al., 2013; Korda \& Itani, 2013). Others have made plea for more studies and attention on social media and evolving technologies as an inclusive public health communication approach (Lefebrvre \& Bornkessel, 2013; Teutsch \& Fielding, 2013).

Surprisingly, as Giustini et al. (2018) have noted, there is little proof to signpost that new technology, social media in particular are being sufficiently employed by both individuals and public health institutions. Therefore, this paper seeks to explore social media usage in health communication and its implications to public health security in Zanzibar. Specifically, the paper seeks to clearly understand the social media role in helping containment of COVID-19 as a new challenge facing the World.

In this study, social media is referred as group of new technologies and digital tools employed for communal health related communication. One of the significant features of social media is its tremendous importance in smoothing the interactivity and incorporation among the general public through the inventive tool known as technology. According to Alsugharyr (2015), social media refers to platforms based on online applications used by individual users and organizations to share news, information and links via online conversion. Social media is also defined as a form of information communication technologies that enable users for networking and interactions (Kapoor et al., 2018). The fast rise of social media in the recent years has been supplemented by wave of people and company firms from various industries pursuing to employ technologies for interactive purposes with customers, friends, family members and other associates. This signifies that these new technologies have changed the way individuals interact barely overemphasizes the condition (Spector \& Kappel, 2012).

Another concept in this paper is health communication. According to Centers for Disease Control and Prevention (2020) in United States, health communication refers to the field and employing communication approaches to notify and inspire decisions and engagements to enhance health issues. Another aspect needs more elaboration in this paper is COVID-19 as a case study in this discussion. The corona virus is defined as respirational illness that affects the health of people. World Health Organization (WHO) declared COVID-19 as syndrome on February 2020. The organization labeled the virus as pandemic illness in march, 2020, signifying that the disease transmission is tremendous fast and high worldwide (WHO, 2020).

There are various approaches social media is used for communication. This defining feature made users and other health related organizations to shift their model of information flow through mainstream media to completely interactive oriented conversation. Whereas a number of community health institutions such as Zanzibar Ministry of Health, Tanzania Food and Drug Association (TFDA), the World Health Organization (WHO) and others as Thackeray et al. (2012) note, have launched social media linkage, the position of social media in developing community health related communication at the individual level is rarely debated. This paper therefore intends to look at social media in public health communication, social media as the inventive means for offline health actions and social media and public health security nexus in order to understand the way social media is used for health communication, the relationship between online social media usage and offline health outcomes and to recommend best strategies for effective using social media for preventing and controlling pandemic disease like corona virus.

\section{LITERATURE REVIEW}

\section{Research on Social Media and Public Health Communication}

Research on social media and public health communication are abundant in the recent years with the development of social media. A review and discussion on the uses and role of social media as public health promoter indicates that there is broad work that has been conducted by many scholars covering a number of topics. The connection between social media and public health communication has appealed a considerable number of scholars with broad agreement that these new technologies are important actors due to their influence to shape and form opinions (Eysenback, 2008; Grajales et al., 2014; Robledo, 2012).

New technologies, specifically social media have become key platforms for public health communication and Eysenback (2008) posits that social media are used by end users for interaction, empowerment and 
communication. It has now altered health related sector the way is practiced. The scholar maintains that through the interactivity and openness, social media have enabled health care providers to have direct engagement to patients and general public at large. This view is supported by Grajales et al. (2014) who advance that social media platforms are potentials in increasing health awareness to users, and patients. According to Social Networks in Health Care (2010), users and consumers are progressively engaging online related information to educate and develop awareness themselves and decide cure options. Robledo (2012) adds that enhancing health communication can be attained if institutions start to realize the potential of social media.

In addition to the strengths of new media technologies in public health, Wilson and Brownstein (2009) contends that one of the major advantages of new media is that it provides well-timed and pertinent information and messages of public health prominence. Supporting this view, the scholars advance that the technologies can be valuable when pursuing timely and trustworthy facts on the spread of infectious diseases. To end this, the scholars conclude that employing and applying timely information can enhance community access public related health shadowing information.

In case of Africa, the power of social media in relation to the development of health awareness among the users, is acknowledged by Fayoyin (2016) who notes that though various strategies have been introduced in employing social media technologies for health campaign, there is a need for more studies in order to have practical standpoint regarding the usefulness and dysfunctional of social media in the community. In a related study on the use of mobile phone for preventing Polio in Somalia, Oxfam (2015) reveals that social media platforms have been considered for eradicating a number of public health related problems challenging African continent including Polio disease. Oxfam advocates that the uses of mobile phones may be the best solution for polio education and restricted delivery of incentive scheme. However, as Fayoyin (2016) notes that, there is a need for a vigorous exploration about the influence of the numerous variables in program distribution so as to avoid reinforcing or underpinning variables in health communication.

Generally, the literature provides significant feature of social media as public health promoter, and there is slight or no intervention in the process of creation and dissemination of health related messages. However, there is lack of literature that specifically explore the current role social media play in prevention and controlling pandemic disease such as COVID-19. Further, whilst this was the case in numerous studies, it is prudent to understand how social media is used and useful in prevention and control of Corona virus in Zanzibar.

\section{Research on Social Media and Offline Health Actions}

The rise of mass protests such as "Stop Quarantine" and "Start Work" in Europe and America has stirred scholarship on the role of social media in such social engagements specifically in this difficult moment of COVID-19 pandemic. To end this, Zhang et al. (2017) note that there is a growing body of research on health communication online but slight attention has been made to the consequences of such deliberation online.

There is extensive work that has discussed the potential of social media in influencing offline health outcomes in different perspectives. The body of literature provides important roadmap in this study to understand how health communication on social media by users in Zanzibar has a relationship with offline health actions and outcomes (Shakya \& Christakis, 2017). The literature on the social media in healthcare is extensive covering usefulness in inspiring the offline health related actions among users in various parts of the world (Althoff et al., 2017).

The scholars consider social media as the definitive tool for people decision regarding their health related issues (Althoff et al., 2017; Shakya \& Christakis, 2017). These perceptions offer significant insights on the current and future roles of social media in public health in Africa and worldwide. However, a crucial aspect that is missing from extensive body of literature is a comprehensive discussion that ascertains the relationship between online health communication discussion and offline health related actions in the wake of coronavirus outbreak. This paper therefore, seeks to explore the relationship between online health related discussion and the offline health actions. 


\section{Research on the Relationship between Social Media and Public Health Security}

The relationship between new media technologies and health security has stirred the interest of a number of scholars with the broad consensus that these technologies are main players due to their power to shape public opinions (Bekalu, McCloud, \& Viswanath, 2019). In view of the advancement and rise of new media technologies, many recent studies have tried to understand how the new media and other related technologies inspire health security (Evariant, 2019).

In recent years, a number of studies have focused on the health security concerns posed by the new media technologies, social media in particular. The scholars have discussed a number of examples social media poses concerns to individual's health (Bekalu, McCloud, \& Viswanath, 2019; Evarient, 2019). Bekalu, McCloud, and Viswanath (2019), in a study on connection of social media with social well- being, posit that the use of social media as a regular social manner could be useful or harmful. The scholars advance that the routine use of social media has positive effects whereas emotional connection has linked to negative consequences. However, the scholars note that the strength of positive outcomes resulted by routine use and negative outcomes inspired by emotional connection depends on the various matters such as economic, social and ethnic issues (Bekalu, McCloud, \& Viswanath, 2019).

A similar approach is also employed by Shakya and Christakis (2017) in a longitudinal study on the use of Facebook and compromised well-being in United States. The scholars confess the influence of social media in promoting public health, but note that the technology use may be connected with increased risk to unfavorable notion such as promoting thin essences hence simplifying access to people connected to anorexic related conducts. It is important that the studies on the integration between social media and public health have been interested by negative perceptions such that highlighting is sited on understanding risks posed by social media (Shakya and Christakis, 2017).

However, the relationship between new media usage and health has now becoming a rising public concern, as Andreassen (2015) noted, pragmatic evidence remains unconvincing. This study also seeks to understand the implications of social media to health security specifically social media role in preventing and controlling COVID-19 pandemic and its implications to users' offline health outcomes. In the light of the literature reviewed and some identified information gaps, this paper poses the following research questions:

\section{Research Questions}

RQ1: How is social media used in prevention and control of coronavirus in Zanzibar?

RQ2: How do online health related messages relate to offline health outcomes?

RQ3: What are the health security implications of health related messages on social media?

RQ4: What approaches and policies can be adopted for use of social media in effective infectious disease containment without compromising health security in Zanzibar?

\section{Theoretical Perspectives}

Theories of communication elucidate the causes and drives which inspire people to employ specific source of getting the required information. According to Users and Gratifications theory (UGT), people have different individual desires, then they will employ source of materials to satisfy those needs (Brandtzaeg \& Heim, 2009). The theory identifies rudimentary types of needs including information, entertainment, personal identity and social interaction. Another theory that is used to study people's behavior and health matters is The Health Belief Model (HBM). The theory which was developed by Rosenstock, Hochbaum and other psychologists in the 1950's posits that individuals are highly expected to adopt preventive measure if they observe that their health is on the high risk, if they sense they are individually vulnerable and if there are low costs than gains to engage in it (Laranjo, 2016).

The study uses Health Belief Model (HBM) and The Users and Gratifications Theory (UGT) to have coherent understanding on social media usage in mitigating COVID-19 infection. Since HBM is widely used to gauge the interplay between perceived threat and protective behavior, this current study seeks to understand the relationship between online activities and offline actions relates to Coronavirus mitigation in Zanzibar. On the other hand, the study also applies UGT to provide comprehensive analysis on why users employ social media 
during pandemic to find information that will help them. These theories will offer clear understanding on why Zanzibar citizens use social media for coronavirus mitigation as well as understanding the interplay between online activities and offline actions.

\section{METHODOLOGY}

This was a qualitative research intended to gain a comprehensive understanding about the uses of social media in mitigating COVID-19 infection and its implications to health security. In this study, social media means any online platform which allows online users to access, generate and distribute content or to partake in online social interaction. Qualitative approaches were adopted for this research for the reason that they offer the required data, attitudes and views of different people (Glaser \& Strauss, 1967). Interview was chosen as the main data collection method due to the fact that it inspires open and free discussion as well as enabling supplement questions.

The study was conducted from March $15^{\text {th }}$ to May $15^{\text {th }}, 2020$. Both face to face and telephone interviews between tutors from Zanzibar Journalism College and some health professionals in Zanzibar were conducted by researchers. Participants in this research involved 15 Zjmmc tutors who are communication experts, and 15 health professionals. We coded tutors in this study as T1, T2, T3... whereas health professionals are coded as HP1, HP2, HP3... Due to the fact that, the utilization of social media for health communication is still an innovative practice, a researcher adopted purposive sampling to obtain participants and their main qualification to participate in this study was that he or she must be social media users.

Our objectives in this study included the social media usage in health communication for COVID-19 mitigation, understanding social media threats to health security during pandemic, the interplay between online health activities and offline health actions as well as strategies for better social media usage in mitigating disease infection during pandemic.

\section{DATA PRESENTATION}

\section{The Usage of Social Media in COVID-19 Mitigation}

The first research question in this study sought to understand the social media usage in health communication during pandemic. In order to precisely understand this question, researchers divided the questions according to the respondents' experience and professions. The first group that involved tutors, the researchers sought to understand how they employ social media for health communication during COVID-19 outbreak, whereas another group included health professionals. In this group, the researchers sought to understand how health professionals use social media platforms during COVID-19 infections.

As regards how tutors used social media for COVID-19 mitigation, 9 respondents out of 15 stated that they used social media during pandemic for searching COVID-19 prevention educational information as well as for knowing COVID-19 infection trends and updates. However, 6 respondents affirmed that they use social media platforms for searching information on treatments alleged to cure or reducing the impact of the COVID-19 in Zanzibar.

As regards to tutors' reactions on the uses of social media for COVID-19 mitigation, T1 said that the low costs and absence of hurdles of entry as well as exceptional interactive features has attracted a lot of people to employ these platforms for getting pertinent information on COVID-19 infections as well as strategies for its mitigation. $\boldsymbol{T} \boldsymbol{1}$ said:

"Social media provides me a better opportunity to receive COVID-19 information that is not filtered. Through these platforms, I can comment any posted Coronavirus related threads with no barriers. When the COVID-19 infections upsurge, I used social media to get COVID-19 prevention education as well as understanding the disease infection's trends and updates".

However, $\boldsymbol{T} \mathbf{1}$ has pointed out that the absence of filtering mechanisms has become one of the main shortcomings in Coronavirus mitigation because of the probability of falsification is very high.

T2 were in supportive social media platforms as important tools for COVID-19 awareness. A T2 said that she used social media for searching for Coronavirus pertinent information that help her to know preventive 
means and some local medicines that alleged to ease and even cure the disease. Against this background, $\mathbf{T 2}$ said:

"When the COVID-19 infections up surged, I decided to turn into social media platforms to understand ways in which I could get rid of that menace. There are many Coronavirus related threads posted on my friends Facebook walls describing ways on how to prevent from getting the infections. On these walls, I also found some local medicines information that I used to take for preventive measurers".

Regarding to health professionals, 11 respondents out of 15 said that, they used social media for providing health education and awareness to the public about COVID-19 prevention as well as searching for better prevention techniques when delivering services for infected. However, 4 health professionals affirmed that they used social media platforms during pandemic for getting feedback for what they post about COVID-19 infections.

In elaborating the use of social media for health awareness for COVID-19 mitigation, HP1 said:

"Despite the fact that we got special training for treating suspected and infected COVID-19 patients, I got supplement knowledge on COVID-19 information from YouTube and other social media platforms for protecting me and my family during pandemic".

\section{The Correlation between Online Health Information and Offline Health Actions}

The second research question in this research sought to understand the interplay between online health information and offline health actions. In order to clearly exploring this type of question, researchers used the theme of alleged COVID-19 treatments practice as a key tester towards interviews' reactions.

Based on the study, both tutors and health professionals reacted persuasively that online health information influenced their offline health actions. 20 interviewees out of 30 assertively confirmed that there is a strong connection between what they saw online and what they practice offline regarding to COVID-19 infection. As regards to tutors' reactions, $\mathbf{T 4}$ clearly affirmed that online health information has assisted him to have broad understanding on various local medicines and treatments that can be used to combat COVID19 and other related diseases. He said:

"Although the outbreak of COVID-19 has brought a lot of detriments in Zanzibar society, I got some knowledge through online health provided information. The major advantage went along with COVID-19 is that I gained much knowledge about the uses of local medicines".

HP2 credited social media through online health information as a main contributor to the reduction of COVID-19 not only in Zanzibar but also in Tanzania at large. $\mathbf{T 2}$ said:

"Social media played a key role in mitigating and reduction of COVID-19 in Zanzibar because many people understood and practiced preventive measures offered through online platforms".

T5 interviewed was in agreement in saluting social media platforms as authorizing tools for influencing people offline health decisions in Zanzibar. "Online health information helped me to understand and practice local medicines publicized on social media platforms. Through online health awareness, I believe it played a major role in minimizing the impact of Coronavirus infection in Zanzibar" T5 added.

The opinion that online health information has influenced people offline health actions in Zanzibar was also asserted with health professionals. HP3 believed that the low hurdles of becoming online user have attracted many people to participate online health related activities. This easy accessibility according to $\boldsymbol{H P} \mathbf{3}$ has made possible to a considerable number of people in Zanzibar to access COVID-19 related information online that influenced them to practice some treatments that assumed to cure or decrease the speedy of COVID-19 infection. He said:

"Social media provides exclusive chance that an individual can attain abundant health information of COVID-19 in different perspectives ranging from prevention to treatment. This convinced large number of online users to practice various local medicines assumed to treat COVID-19 infection. During spike rise of Coronavirus infections, there were a number of hurdles and conditions for people to get health awareness and education on the pandemic, therefore, the remaining opportunity was to utilize social media for understanding general information about prevention and treatment. That is undeniable connection of online platforms power to individual offline health outcomes". 
However, the expert believed that low or even absence of filters on social media platforms viewed as one of the main shortcomings in positive connection between online health activities and offline health actions as the risk of misinformation about the authenticity of COVID-19 treatment was very high. He clarified that the dramatic advancement of new technologies has overtaken the existing online content regulations making health education on social media to be a game with no guidelines, hence making it too unsafe platform for health communication especial during pandemic where some people tend to use social media for spreading misinformation.

However, 10 respondents were in contention that there is a weak connection between what they saw online and what they practice offline regarding Coronavirus. This signifying that despite the fact that they were using social media to get information of preventing from COVID-19 infection, they were not inspired to practice what they saw online. Though, they agreed that online information regarding COVID-19 helped them to take some prevention measures, they were reluctant to practice alleged treatments discussed on social media because of the strict existing laws that prohibit any form of protests including social distancing laws and quarantines. $\mathbf{T 6}$ said: "the use of social media for mitigating disease specifically coronavirus is very important but the increasing risk of misinformation generated through these platforms, has made me to stay away with suggestions provided by people about COVID-19 because many health related threads regarding COVID-19 were posted by anonymous users, thus lost credibility to be useful for fighting the infection".

\section{Threats Social Media Pose to Health Security}

The study also sought to understand opinions of the interviewees on the use of social media in COVID-19 mitigation and whether they perceived it as threats to people's health. In order to clear understanding, the study sought to get elucidation from interview with journalism tutors and health professionals. The results from the interviews show that 18 interviewees regardless their professionals affirmed that the use of social media during pandemic in Zanzibar posed threats to people's health whereas 12 respondents had divergent views on the matter. They advanced that many social media platforms are used by non-identified users to post misinformation and fake news that caused serious and unnecessary confusion to the public during pandemic.

From the opinion of the $\boldsymbol{T 7}$, said that the risk posed by new media technologies specifically social media have not only posed a threat to individual person but also to the health system in Zanzibar and other African countries. He said that if large number of people believe and practice whatever they saw online, can have a dangerous repercussion to the public and local hospitals due to the fact many posted messages online including treatments of certain diseases are not verified by responsible organizations. He said:

"Despite the fact that the local medicines have played the unforgettable role as the ongoing efforts to contain or reduce the sharpness of the Coronavirus in Zanzibar, people who use these local medicines should first get directives from the health specialists about the amount and the time these herbalists should be used".

HP4 from the private organization acknowledged that the uses of social media for health communication pose threats to health on users who just take anything posted on social media platforms for granted. He said it is unfortunate that almost all forms of these platforms currently post misinformation and fake news that threaten not only users' health but also national security. "The current trends of releasing fake data that list number of infected by coronavirus is an example of the recent misuse of social media in mitigating Coronavirus in Zanzibar. The non-verified number usually claims that almost the selected hospitals dealing with COVID-19 are loaded. However, when one tries to trace its verification, it appears that information has no official bases". HP4 said.

However, 12 interviewees were in contrary to the matter. This group of interviewees believes that social media has profound contribution to the COVID-19 mitigation in Zanzibar and they claimed that these platforms have only negative repercussions to the people who lack new media literacy. The opposed view is well clarified by $\mathbf{T} \mathbf{8}$. She said that social media can only pose threat to people health who always believe what they saw online without make any verification of the information posted. She advanced that during pandemic such as Coronavirus one should be care in health information selection.

"Social media platforms pose no threats to the users who have media literacy skills and can only be risk to those who believe every information posted online". T8 claimed. 
Generally, based on the findings, it suggests that large number of interviews (18) believe that the use of social media pose some threats to citizens health because the possibility of misinformation is very high whereas other group of interviewees (12) view social media platforms as opportunity rather than threat. This group believes that the platforms can only have negative consequences to people's health those who lack online media literacy.

\section{DISCUSSION}

The previous sessions presented results to the research questions about the uses of social media in containment Coronavirus and its implications of such employment on individual's health security in Zanzibar. This session provides main results and draw insights that may contribute to the body of knowledge on the use of social media in health communication during the pandemic. The crucial strategies to creating sense from the findings were main research questions that were designed from the beginning of the study. Consequently, the discussion grasps light on the health security implications of the social media in health communication, the uses of social media and offline health outcomes as well as strategies that could be undertaken for effective use of social media in Zanzibar and other developing countries with related environments.

\section{Social Media Use: A Practical Tool during Pandemic}

The aim of online health communication is for people to search for health related information in order to solve their health concerns. By doing so they try to participate on various online activities where they meet different health related messages that may influence their offline actions. These goals are well articulated by Health Believe Model which proposes that individuals are likely expected to take preventive measures if they see the threat on their health is on high risk, or if they realize they are personally vulnerable and there are less costs than advantages to engaging in it (Laranjo,2016). This explanation is also noted by Brandtzaeg and Heim, (2009) when characterized the drives that inspire people to select specific source for getting information. According to Users and Gratifications Theory, people have different individual desires, then they will employ source of materials to satisfy those necessities (Brandtzaeg \& Heim, 2009). This therefore implies that social media platforms are widely used in Zanzibar for COVID-19 information due to the fact that these platforms offer pertinent information for coronavirus mitigation including possible cure.

This is noted in the findings in the current study relates to the usage of social media in COVID-19 mitigation. The majority number of interviewees (20) stated that they used social media during pandemic for searching COVID-19 prevention educational information as well as for searching information on treatments alleged to cure or reducing the impact of the COVID-19 in Zanzibar. These findings are supported by Cook et al. (2008) that during the pandemic people are interested in following social media by searching for treatment that may solve their health concerns.

\section{Lack of Internet Media Literacy Increases Risk to People's Health during Pandemic}

The data presented reveal that some participants (12) in this study believed that the social media use in mitigating Coronavirus can only pose threat to users' health if they lack Internet media literacy. Their argument is based on the fact that on social media, people are able to post whatever they like without making any verification and they claimed that if user have some awareness and education on how to use social media, then there will be fewer threats to user's health because they will be able to detect misinformation on the threads posted. The findings are acknowledged by Dominick et al. (2009) in their study on the significance of using computer literacy for preventive health programs. Thus, based on the data in this study, social media platforms can be effectively used for health communication specifically COVID-19 mitigation if online users get digital media literacy during pandemic.

\section{Presence of Strict Online Content Laws Limits the Online and Offline Connection}

There are great hopes of the inspiration of social media in intensifying the freedom of expression especially in spreading messages for developing health awareness in Zanzibar as replicated by the findings from the interviews conducted. The aim of online health discussion is for people to voice their sentiments on 
the matters touching the public health and by doing that they try to inspire government to implement their concerns.

However, one of the issues that has caused the disconnection between online actions and offline actions according to the findings of the study is fear among online users due to the difficulties that online regulators face in managing misinformation and fake news flooding on social media. Another worry that limits disconnection online and offline actions according to respondents is anti-demonstration laws in Tanzania. Some respondents raised their fear that despite the fact that they were willing to express their discontent on social distancing laws through offline protests, they were not ready for confrontation with security forces.

When asked whether they can engage offline protests after they receive invitation on social media, 16 interviewees stated that they were not willing to participate offline any form of protests about social distancing and quarantine laws. 9 interviewees confirmed that they were only willing to engage any form of protests if they are permitted by authorities. Only 5 respondents claimed that they were ready to participate in the non-permitted protests. These findings are acknowledged in the studies that reveal that some African citizens unwillingness, to engage in the events that may lead to confrontation with law enforcers (Masungunure, 2006; Mills, 2004).

\section{Threats and Risks Social Media Pose on User's Health}

This study established that there was a lack of empirical evidence on the employment of social media specifically in Zanzibar to demonstrate how the people are engaging online platforms in health communication as well as rationalize public health security concerns posed by social media usage in the period of disease outbreak. One of the important questions for this research, therefore wanted to comprehend how the use of social media for health communication pose a threat to the users and public health at large. From this question, the research reveals that majority of the interviewees (18) agreed that social media platforms pose a number of threats and risks to users' health. Many people posited that while there was a time no official COVID-19 infection updates from government, this gap created a chance for social media to spread rumor and misinformation on coronavirus infection and death toll data that created a fear and confusion to the public. This concern was also noted by HP1 from private hospital who advanced that social media has caused many challenges to the people that has direct consequence to their health and public at large. He said that when the misinformation that alleged that hospitals are overloaded by coronavirus infected people spread, many people who have other diseases escaped to go hospital to avoid what they call negligence.

The results are noteworthy as they offer empirical evidence to a matter that has been highly discussed from imaginary perspectives with no comprehensible evidence of the actual benefits and risks instigated by social media in health communication specifically containment of coronavirus infection. This concern was also put into consideration in the literature review by Alsughayr (2015) using social media in healthcare. A number of scholars have also affirmed the risks posed by social media to individual and public health in general (Pathipati, 2014; Weaver et al., 2012). While these scholars admit that the threats posed by social media to people's health, they however lack new empirical evidence on the degree of risks especially during pandemic such as COVID-19 infections.

In light of these results that reveal the new and clear evidence from the current role of social media and its impact to realistic live hoods, it is convincing to draw the conclusion that there is considerable risk and threat to public health in engaging social media for health communication in Zanzibar specifically during pandemic like Coronavirus infections based on the sentiments from the interviewees.

\section{CONCLUSION}

The growth of social media and other new technology platforms has mainly hailed with positive viewpoint and also identify their limitations. It was discussed that positive aspects advance that social media platforms are the powerful tools in creating the informed and responsible society during pandemic because of interactivity and low barrier of entry; the features that have qualified social media for magnificently consolidating and harmonizing online users and created groups to share various health related information in order to develop awareness for containment diseases in various parts of the world. On the other hand, 
negative views means that social media are kinds of platforms that are just used for spreading misinformation and threats to the public especially during disease outbreak that create fear and confusions.

It can be noted that this research acknowledged the leading discussions on social media in healthcare and tried to find out practical evidence to contribute to academic knowledge on the effective employment of social media in order to upsurge opportunities in COVID-19 containment while minimizing the risks on health. In light of empirical findings and insights drawn from the literature, the following conclusions can be drawn from the study. The research has revealed that there is substantial evidence that social media platforms are very influential tools in facilitating COVID-19 mitigation because of its immediacy of delivering health information and awareness to the public.

Furthermore, the study exposed mixed views on the issue of online and offline connection whereby correspondence and disparity emerged. The study initially, revealed that there is a strong connection between what they saw online and what they practice offline regarding to COVID-19 infection. The connection noted is that 20 respondents affirmed that they had frequently practiced treatments advocated online that can cure coronavirus. However, the study observed that there was disconnection on health actions advocated online against the unwillingness of the people to reflect such practices of offline engagements. This disconnection was noted on the issue of participating offline rallies to protest social distancing laws and quarantine related orders imposed authorities in which 10 respondents showed no willingness to participate. This disparity, however, according to the study, was caused by a number of reasons such as strict online content laws that provide severe punishment for any user convicted to post information that deemed to be seditious or going against cyber security laws.

Regarding to health security implications of the use of social media in health communication, the research has drawn a number of insights that was critically analyzed. The research noted the literature that reflects the current study that despite the fact that social media platforms, have accidentally associated with threats and risks, they have played undisputable role in helping containment of COVID-19 infections in Zanzibar due to its immediacy in updating educative and informative news. In this evidence, social media have become important tools in accelerating fight against pandemic diseases worldwide as witnessed in the context of Zanzibar.

\section{RECOMMENDATIONS}

In the light of data of this research, a number of recommendations for future studies are offered.

Despite risks, social media pose to public health as occupied by misinformation and unverified news, people should not be afraid of change inspired by globalization innovations including new media technologies. Zanzibar citizens are great fans of social media and this must be exploited for Coronavirus containment.

Since compliance of health's directives on COVID-19 containment implicates a behavioral change, the communication of this advocacy should not only focus on online users but also the whole community specifically vulnerable groups such as people exceed 60 years old (Vally, 2020). These groups should be intentionally educated that they are at high risk on fatality if they are infected. Therefore, this campaign should involve ambassadors such as film actors and music stars for effective inspiration.

Further, more health related advocacies on COVID-19 should be engaged in both social media and traditional means of conveying information such as mass media, music shows, workshops and sports. This strategy will make possible for considerable number of people including those who are not fans of new media platforms.

Finally, As the previous literature (Dominick et al., 2009) acknowledged the significance of using computer literacy for preventive health programs as well as the interviewees' concerns in this study about engaging these new technologies for health communication, media and information literacy approach should be put on high consideration on how social media platforms should be effectively used without compromise public health. 


\section{REFERENCES}

Alaughary, A. R. (2015). Social media in healthcare: Uses, risks and barriers. Saudi J Med Sci, 3, 105-111. https://doi.org/10.4103/1658-631X.156405

Althoff, T., Jindal, P., \& Leskovec, J. (2017). Online Actions with Offline Impact: How Online Social Networks Influence Online and Offline User Behavior. Proceedings of the International Conference on Web Search \& Data Mining. International Conference on Web Search \& Data Mining, 2017, pp. 537-546. https://doi.org/10.1145/3018661.3018672

Andreassen, C. S. (2015). Online social network site addiction: A comprehensive review. Current Addiction Reports, 2, 175-184. https://doi.org/10.1007/s40429-015-0056-9

Bekalu, M. A., McCloud, R. F., \& Viswanath, K. (2019). Association of Social Media Use With Social Well-Being, Positive Mental Health, and Self-Rated Health: Disentangling Routine Use From Emotional Connection to Use. Health Education \& Behavior, 46(2_suppl), 69S-80S. https://doi.org/10.1177/1090198119863768

Brandtzaeg, P. B., \& Heim, J. (2009). Why people use social networking sites. In International Conference on Online Communities and Social Computing, 143-152. https://doi.org/10.1007/978-3-642-02774-1_16

Centers for Disease Control and Prevention. (2020). Health Communication Basics: What is health communication. U.S. Department of Health and Human Services. Retrieved from https://www.cdc.gov/healthcommunication/healthbasics/WhatlsHC.html

Chan, A. K. M., Nickson, C. P., Rudolph, J. W., Lee, A., \& Joynt, G. M. (2020). Social media for rapid knowledge dissemination: early experience from the COVID-19 pandemic. Anaesthesia. https://doi.org/10.1111/anae.15057

Chou, W. S., Prestin, A., Lyons, C., \& Wen, K. (2013). Web 2.0 health promotion: reviewing the current evidence. Am J Public Health, 103, e9-18. https://doi.org/10.2105/AJPH.2012.301071

Cook, D. A., Levinson, A. J., Garside, S, Dupras, D. M., Erwin, P. J., \& Montori, V. M. (2008). Internet-based learning in the health professions: a meta-analysis. The Journal of the American Medical Association, 300(10), 1181-1196. https://doi.org/10.1001/jama.300.10.1181

Digital 2020. (2020). Tanzania: April Global Stats hot Report.

Dominick, G., Friedman, D., \& Hoffman-Goetz, L. (2009). Do we need to understand the technology to get to the science? A systematic review of the concept of computer literacy in preventive health programs. Health Educational Journal, 68(4), 296-310. https://doi.org/10.1177/0017896909349289

Evariant. (2019). The Role of Social Media in Healthcare: Benefits \& Challenges.

Eysenback, G. (2008). Medicine 2.0: Social networking, collaboration, participation, apomediation, and openness. Journal of Medical Internet Research, 10(3) 1-10. https://doi.org/10.2196/jmir.1030

Fayoyin, A. (2016). Engaging Social Media for Health Communication in Africa: Approaches, Results and Lessons. J Mass Communication Journalism, 6, 315. https://doi.org/10.4172/2165-7912.1000315

Giustini, D., Ali, S. M., Fraser, M., \& Kamel Boulos, M. N. (2018). Effective uses of social media in public health and medicine: a systematic review of systematic reviews. Online journal of public health informatics, 10(2), e215. https://doi.org/10.5210/ojphi.v10i2.8270

Glaser, B. G., \& Strauss, A. (1967). The Discovery of Grounded Theory: Strategies for Qualitative Research. Hawthorne, NY: Aldine Transaction.

Gough, A., Hunter, R. F., Ajao, O., Jurek, A., McKeown, G., Hong, J., et al. (2017). Tweet for Behavior Change: Using Social Media for the Dissemination of Public Health Messages. JMIR Public Health Surveill., 3(1), e14. https://doi.org/10.2196/publichealth.6313

Grajales, F. J., Sheps, S., Kendall, H. O., Novak-Lauscher, H., \& Eysenbach, G. (2014). Social media: A review and tutorial of applications in medicine and health care. J Med Internet Res, 16, e13. https://doi.org/10.2196/jmir.2912

Honigsbaum, M. (2013). Regulating the 1918-19 pandemic: flu, stoicism and the Northcliffe press. Med Hist., 57(2), 165-185. https://doi.org/10.1017/mdh.2012.101

Kapoor, K. K., Tamilmani, K., Rana, N. P., et al. (2018). Advances in Social Media Research: Past, Present and Future. Inf Svst Front, 20, 531-558. https://doi.org/10.1007/s10796-017-9810-y

Korda, H., \& Itani, Z. (2013). Harnessing social media for health promotion and behavior change. Health Promot Pract., 14, 15-23. https://doi.org/10.1177/1524839911405850 
Laranjo, L. (2016). Social Media and Health Behavior Change. In Participatory Health Through Social Media (pp. 83-111). Academic Press. https://doi.org/10.1016/B978-0-12-809269-9.00006-2

Lau, A. Y. S., Gabarron, E., Fernandez-Luque, L., \& Armayones, M. (2012). Social Media in Health -- What are the Safety Concerns for Health Consumers?. HIM J. 41(2), 30-35. https://doi.org/10.1177/183335831204100204

Lefebvre, R. C., \& Bornkessel, A. S. (2013). Digital social networks and health. Circulation, 127, 1829-1836. https://doi.org/10.1161/CIRCULATIONAHA.112.000897

Merchant, R. M., \& Lurie, N. (2020). Social Media and Emergency Preparedness in Response to Novel Coronavirus. JAMA. https://doi.org/10.1001/jama.2020.4469

Oxfam (2015). Using Mobile Phones for Polio Prevention in Somalia: An evaluation of the 2013-14 interactive messaging and mobile voucher system deployed in hard to reach areas in Somalia.

Robledo, D. (2012). Integrative use of Social Media in Health Communication. Online Journal of Communication and Media Technologies, 2(4), 77-95. https://doi.org/10.29333/ojcmt/2400

Sebenius, A., \& Egkolfopoulou, M. (2020). Far-Right Social Media Helps Stir Protests Over Quarantines. Bloomberg website.

Shakya, H. B., \& Christakis, N. A. (2017). Association of Facebook Use With Compromised Well-Being: A Longitudinal Study. American Journal of Epidemiology, 185(3), 203-211. https://doi.org/10.1093/aje/kww189

Social networks in health care: Communication, collaboration and insights. (2010). Retrieved from https://www.deloitte.com/assets/Dcom-UnitedStates/Local\%20Assets/Documents/US_CHS_2010Social Networks_070710.pdf

Spector, N., \& Kappel, D. M. (2012). Guidelines for using electronic and social media: The regulatory perspective. Online J Issues Nurs, 17, 1.

Teutsch, S. M., \& Fielding, J. E. (2013). Rediscovering the core of public health. Annu Rev Public Health, 34, 287299. https://doi.org/10.1146/annurev-publhealth-031912-114433

Thackeray, R., Beiger, B. L., Smith, A. K., \& Van Wagenen, S. B. (2012). Adoption and use of social media among public health departments. BMC Public Health, 12, 242. https://doi.org/10.1186/1471-2458-12-242

Tustin, N. (2010). The role of patient satisfaction in online health information seeking. J Health Commun., 15(1), 3-17. https://doi.org/10.1080/10810730903465491

Vally, H. (2020). Why are older people more at risk of coronavirus?

WHO. (2020, 10 03). Naming the coronavirus disease (COVID-19) and the virus that causes it. https://doi.org/10.46945/bpj.10.1.03.01

Zhang, X., Guo, X., Lai, K.-h., Yin, C., \& Meng, F. (2017). From offline healthcare to online health service: The role of offline healthcare satisfaction and habits. Journal of Electronic Commerce Research, 18, 138-154.

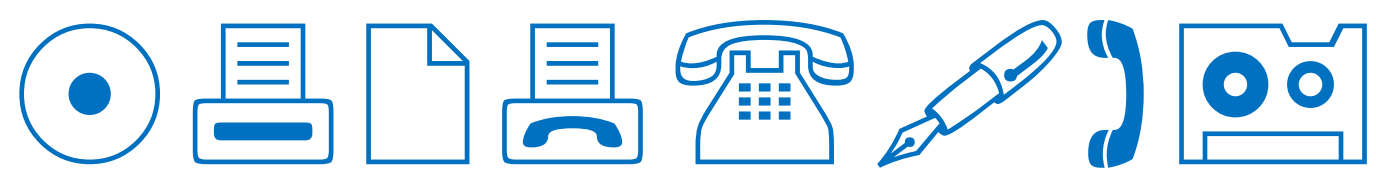

